\title{
An Analysis of the Mutual Publications of Anatomists and Otorhinolaryngologists: A Bibliometric Study based on the Web of Science Database
}

\author{
Ahmet Mahmut Tekin ${ }^{1}$ (D), ilhan Bahşi ${ }^{2}$ (D) \\ ${ }^{1}$ Klinikum Bad Salzungen, Department of Otorhinolaryngology, Bad Salzungen, Germany \\ ${ }^{2}$ Gaziantep University, Faculty of Medicine, Department of Anatomy, Gaziantep, Turkey
}

ORCID ID: A.M.T. 0000-0003-1604-3382; i.B. 0000-0001-8078-7074

Citation: Tekin AM, Bahsi I. An analysis of the mutual publications of anatomists and otorhinolaryngologists: a bibliometric study based on the web of science database. Tr-ENT 2021;31(4):86-93. https://doi.org/10.26650/Tr-ENT.2021.1033996

\begin{abstract}
Objective: The aim of this study is to bibliometrically examine the mutual studies in the fields of anatomy and otorhinolaryngology (ORL) recorded in the Web of Science (WoS) database between 1980-2020.

Material and Methods: The mutual publications of anatomists and otolaryngologists on 31.01 .2021 are listed in the Science Citation IndexExpanded category of the Advanced Search section of the WoS database. Thus, in the search field tags, Department of Anatomy for anatomists and Department of Ear, Nose, and Throat (ENT) or Department of Otorhinolaryngology or Clinic of ENT or Clinic of Otorhinolaryngology for otolaryngologists were used for the address section. Publications from 2021, meeting abstracts, proceedings papers, early accesses, and book chapters were excluded. After the exclusion criteria were applied, the bibliometric characteristics of the remaining publications were examined. Results: After the exclusion criteria were applied, 1395 articles were found. The total number of citations made to these articles was 42537, and at least one citation was made to 1279 of the 1395 articles (91.68\%). The h-index of these articles was 82 , and the average number of citations was 30.49. In these articles, the most frequently used first five keywords were immunohistochemistry (44 times), rat (39 times), cochlea (38 times), anatomy (36 times), and facial nerve (27 times).

Conclusion: The results of our bibliometric study which evaluated the last 40 years of data in terms of networks, collaborations, and institutions could be an inspiration and source for future researchers. We may state that with the increasing technology, the applicability of interventional methods in the field of ORL might be increased by conducting more anatomical studies and yield safer results.
\end{abstract}

Keywords: Anatomy, otorhinolaryngology, article, bibliometric analysis

\section{INTRODUCTION}

Anatomy is one of the oldest fields of medicine that examines the organs that make up the body and the functionality between these organs $(1,2)$. In this long process, the mysteries of the human body have become more understandable thanks to anatomical dissections (1). Especially with the development of high-resolution imaging methods in the last half-century, radiological and clinical studies have been added to anatomic cadaver studies (3). Continuously increasing technological developments have also increased the capacity of medical imaging techniques and have enabled a more detailed and accurate understanding of anatomical structures (4). In this way, the functions and anatomy of these structures and the relationship between them can be investigated in more detail, and solutions are sought for complex clinical situations (5). Thanks to many anatomical studies in the field of otorhinolaryngology (ORL), a more detailed understanding of the structures has been provided, the relationship of these structures with clinical situations can be evaluated, and even the surgical methods to be applied can be planned (6-9).

Many researchers need to collaborate in medical publications, unlike in other fields (10). This is because co-authorship is essential in the emergence of publications in the medical field (11). Bibliometric analysis is gaining in importance and evaluates existing research data accurately and efficiently on an evidence-based basis $(12,13)$. Bibliometric analysis is a 
compelling method for predicting the change and evolution of a research field $(11,13)$. It can also provide evidence for a better understanding of the developmental trend in a particular area $(14,15)$. Bibliometry evaluates the productivity of countries and institutes, as well as objective analysis such as a change in research topics $(15,16)$.

The Web of Science (WoS) database is one of the most popular databases used in bibliometric research today $(13,17)$. One of the most critical criteria of international productivity is the number of articles in the WoS database and the number of citations made to these articles. Since this criterion is seen as an indicator of quality, it can be widely used in the evaluation of countries, institutions, and academicians (17).

As a result of the detailed literature review, it was seen that although there have been separate bibliometric studies conducted in the field of anatomy $(5,11)$, and ORL $(18)$, no bibliometric study evaluating the joint publications of both fields was found.

The aim of this study is to bibliometrically examine the joint studies in the fields of anatomy and ORL recorded in the WoS database between 1980-2020.

\section{MATERIAL AND METHODS}

The mutual publications of anatomists and otolaryngologists on 31.01.2021 are listed in the Advanced Search section of the WoS database. Thus, in the search field tags, Department of Anatomy for anatomists and Department of Ear, Nose, and Throat (ENT) or Department of Otorhinolaryngology or Clinic of ENT or Clinic of Otorhinolaryngology for otolaryngologists were used for the address section [AD= (Dept ENT* OR Dept Otorhinolaryngol* OR ENT Clin* OR Otorhinolaryngol Clin*) AND $A D=($ Dept Anat*)].
Firstly, in the index section of the WoS, the Science Citation Index-Expanded ( $\mathrm{SCl}-\mathrm{E})$ category was selected. Later, publications from 2021, meeting abstracts, proceedings papers, early accesses, and book chapters were excluded. After the exclusion criteria were applied, bibliometric characteristics of the determined publications, such as the distribution of the country and institutes, distribution of keywords, the journals they were published in, number of articles, and number of citations, were examined. Vosviewer (Visualizing scientific landscapes) software was used for the detailed analysis of bibliometric data (12).

\section{RESULTS}

As of 31.01.2021, the number of articles published mutually by anatomists and otorhinolaryngologists between 1980-2020 in $\mathrm{SCl}-\mathrm{E}$ indexed journals in the WoS database was determined as 1596. After the exclusion criteria was applied, 1395 articles were found. The distribution of these articles by year is given in Figure 1. It was determined that the number of citations made to these articles was 42537, and the distribution of citations by years is given in Figure 2. It was determined that at least one citation was made to 1279 of 1395 (91.68\%) articles. The h-index of these articles was 82 , and the average number of citations was 30.49 .

The top 25 countries with the most articles are shown in Table 1. The first five of these countries were Japan ( $n: 303,21.72 \%)$, the USA (n: 301, 21.58\%), Germany (n: 223, 15.99\%), South Korea (n: 178, 12.76\%), and Turkey ( $\mathrm{n}: 127,9.10 \%)$, (since studies with authors from more than one country were not excluded in this distribution, the total value was more than $100 \%)$.

The number of publications from the top 20 most productive institutes is shown in Table 2. The top 5 ranks were Yonsei University ( $n: 81,5.81 \%)$, Umea University ( $n: 72,5.16 \%)$, the

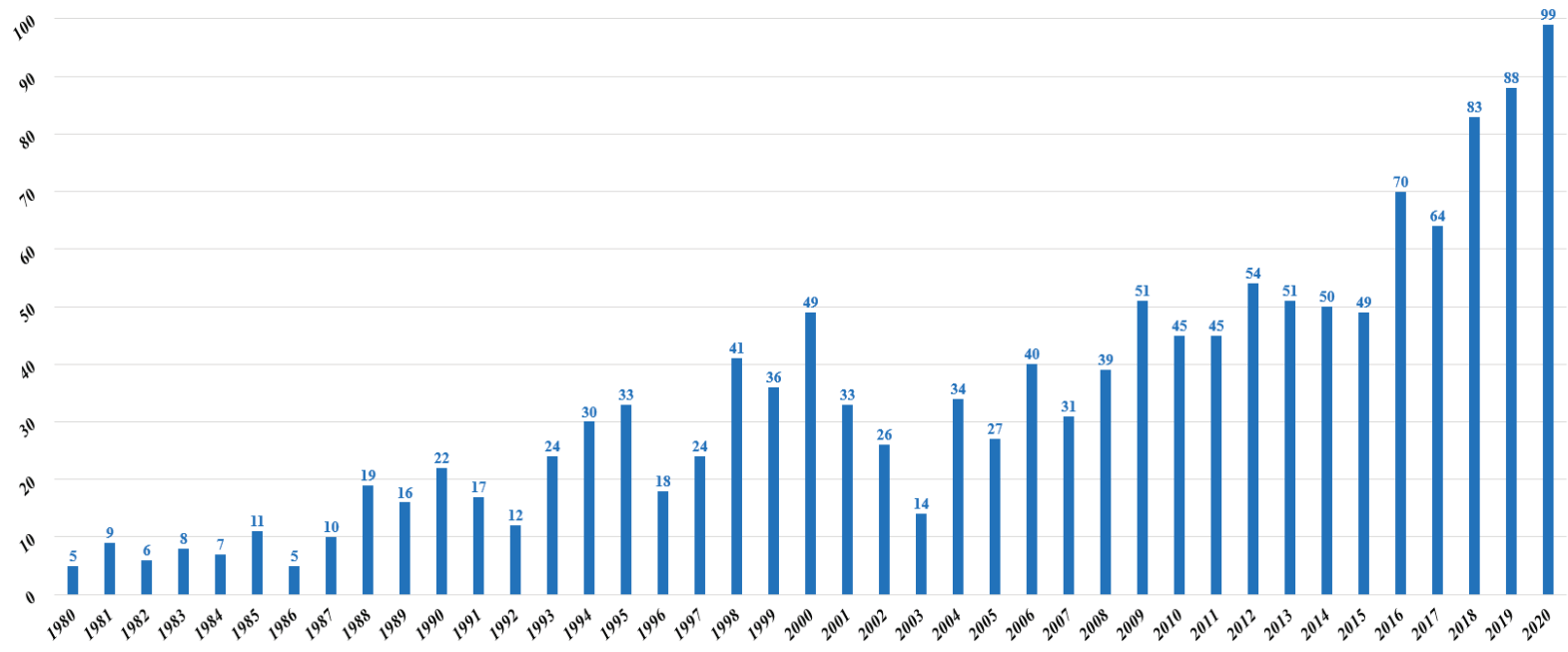

Figure 1: Annual trend of publications on analysis of mutual publications of anatomists and otorhinolaryngologists (1980-2020). 


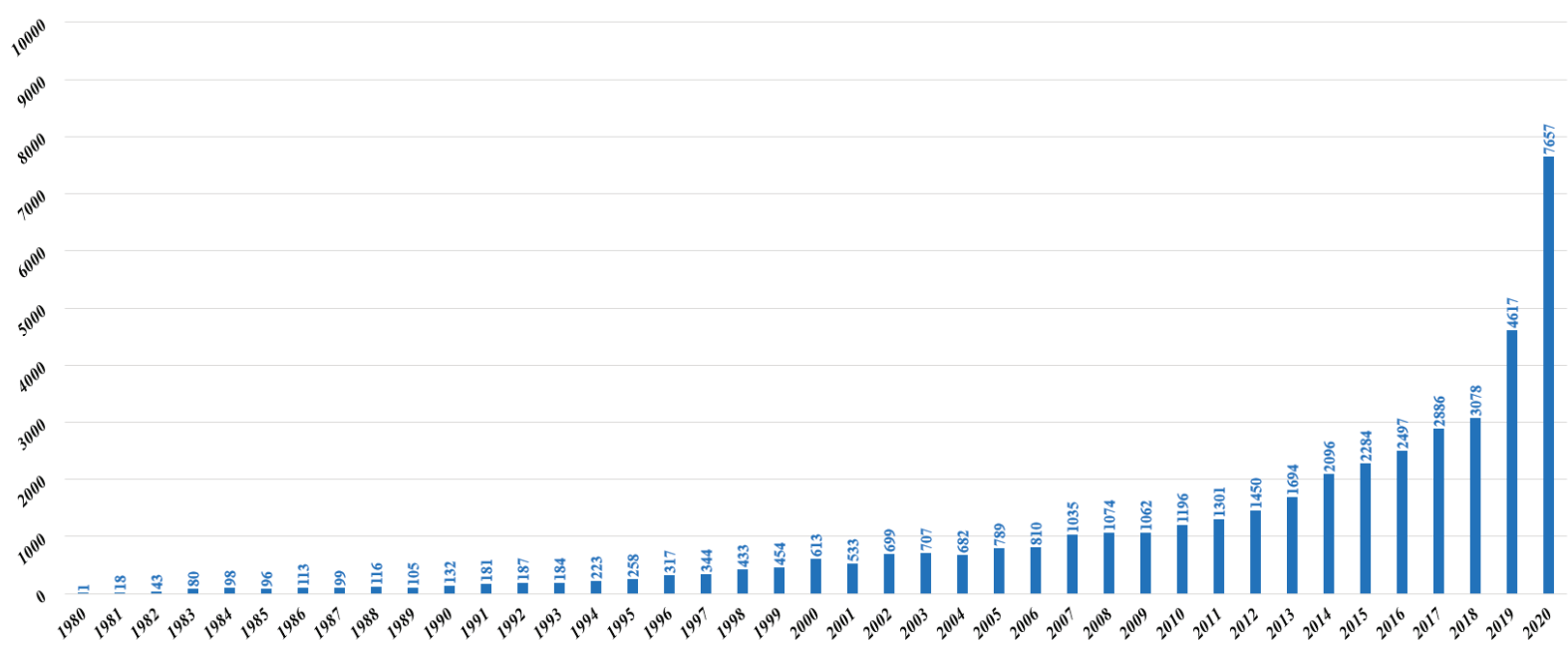

Figure 2: Annual trend of total citations on analysis of mutual publications of anatomists and otorhinolaryngologists (1980-2019).

Table 1: The number of mutual publications of anatomists and otorhinolaryngologists of the top 25 countries.

\begin{tabular}{|c|c|c|}
\hline Country & Number of publications & Percent \\
\hline Japan & 303 & 21.720 \\
\hline USA & 301 & 21.577 \\
\hline Germany & 223 & 15.986 \\
\hline South Korea & 178 & 12.760 \\
\hline Turkey & 127 & 9.104 \\
\hline Sweden & 114 & 8.172 \\
\hline Peoples R China & 94 & 6.738 \\
\hline Netherlands & 80 & 5.735 \\
\hline France & 77 & 5.520 \\
\hline Australia & 75 & 5.376 \\
\hline Belgium & 73 & 5.233 \\
\hline England & 70 & 5.018 \\
\hline Italy & 68 & 4.875 \\
\hline Spain & 68 & 4.875 \\
\hline Canada & 60 & 4.301 \\
\hline Finland & 57 & 4.086 \\
\hline India & 55 & 3.943 \\
\hline Austria & 53 & 3.799 \\
\hline Greece & 50 & 3.584 \\
\hline Norway & 41 & 2.939 \\
\hline Switzerland & 41 & 2.939 \\
\hline Brazil & 39 & 2.796 \\
\hline Romania & 37 & 2.652 \\
\hline Iran & 34 & 2.437 \\
\hline Portugal & 33 & 2.366 \\
\hline
\end{tabular}

Table 2: The number of mutual publications of anatomists and otorhinolaryngologists of the top 20 institutes.

\begin{tabular}{lcc}
\hline Institute & $\begin{array}{c}\text { Number of } \\
\text { publications }\end{array}$ & Percent \\
\hline Yonsei University & 81 & 5.806 \\
Umea University & 72 & 5.161 \\
University of California System & 67 & 4.803 \\
University of Cologne & 61 & 4.373 \\
Kyushu University & 48 & 3.441 \\
Chinese University of Hong Kong & 45 & 3.226 \\
Karolinska Institutet & 41 & 2.939 \\
Kyung Hee University & 41 & 2.939 \\
Seoul National University & 40 & 2.867 \\
University of Helsinki & 39 & 2.796 \\
University of Oslo & 36 & 2.581 \\
Johns Hopkins University & 35 & 2.509 \\
National Institutes of Health & 35 & 2.509 \\
University of Western Australia & 35 & 2.509 \\
University System of Maryland & 35 & 2.509 \\
Friedrich Schiller University of Jena & 34 & 2.437 \\
Harvard University & 33 & 2.366 \\
State University System of Florida & 33 & 2.366 \\
University of Barcelona & 33 & 2.366 \\
University of Maryland Baltimore & 32 & 2.294 \\
\hline
\end{tabular}


Table 3: The number of mutual publications of anatomists and otorhinolaryngologists of the top 25 journals.

\begin{tabular}{|c|c|c|}
\hline Journal & $\begin{array}{l}\text { Number of } \\
\text { publications }\end{array}$ & Percent \\
\hline Acta Oto Laryngologica & 78 & 5.591 \\
\hline European Archives of Oto Rhino Laryngology & 56 & 4.014 \\
\hline Laryngoscope & 36 & 2.581 \\
\hline Hearing Research & 35 & 2.509 \\
\hline Journal of Laryngology And Otology & 28 & 2.007 \\
\hline Annals of Otology Rhinology And Laryngology & 23 & 1.649 \\
\hline Surgical And Radiologic Anatomy & 23 & 1.649 \\
\hline Brain Research & 21 & 1.505 \\
\hline Annals of Anatomy Anatomischer Anzeiger & 18 & 1.290 \\
\hline $\begin{array}{l}\text { International Journal of Pediatric } \\
\text { Otorhinolaryngology }\end{array}$ & 16 & 1.147 \\
\hline Neuroscience Letters & 15 & 1.075 \\
\hline Auris Nasus Larynx & 14 & 1.004 \\
\hline Clinical Anatomy & 14 & 1.004 \\
\hline Otolaryngology Head And Neck Surgery & 14 & 1.004 \\
\hline Otology Neurotology & 14 & 1.004 \\
\hline Plos One & 14 & 1.004 \\
\hline Journal of Neuroscience & 13 & 0.932 \\
\hline $\begin{array}{l}\text { Romanian Journal of Morphology And } \\
\text { Embryology }\end{array}$ & 13 & 0.932 \\
\hline Cell And Tissue Research & 12 & 0.860 \\
\hline Lancet & 12 & 0.860 \\
\hline Neuroscience & 12 & 0.860 \\
\hline Journal of Craniofacial Surgery & 11 & 0.789 \\
\hline Experimental Neurology & 10 & 0.717 \\
\hline Scientific Reports & 10 & 0.717 \\
\hline American Journal of Rhinology Allergy & 9 & 0.645 \\
\hline
\end{tabular}

University of California System ( $\mathrm{n}: 67,4.80 \%$ ), the University of Cologne (n: 61, 4.37\%) and Kyushu University (n: 48, 3.44\%).

The top 25 journals with the most articles are shown in Table 3. The first five of these journals were Acta Oto Laryngologica ( $n$ : 78, 5,59\%), European Archives of Oto Rhino Laryngology ( $n: 56$, 4,01\%), Laryngoscope (n: 36, 2,58\%), Hearing Research (n: 35, $2.50 \%$ ), and Journal of Laryngology and Otology (n: 28, 2.00\%).

By using VoSviewer software, the distribution of the top 20 most used keywords in the examined articles were visualized and can be seen in Figure 3. The first five keywords are immunohistochemistry (44 times), rat (39 times), cochlea (38 times), anatomy (36 times), and facial nerve (27 times). By using VoSviewer software, it was determined that there was a significant change in the use of keywords between 2006-2012 (Figure 4).

By using VoSviewer software, the distribution of the top 50 most used words in the abstract of these articles were visualized and are shown in Figure 5. It was determined that there was a significant change in the use of these words between 2007-2012 (Figure 6).

\section{DISCUSSION}

Scientific publications are generally accepted as the objective parameters of the scientific success of any institution or researcher, as well as being accepted as a way to share new medical information and current clinical practices with a wide audience (19). The productivity of countries, institutions, and international cooperation in a particular field of research can be evaluated using the bibliometric method of analysis (20).

In the present study, Japan and the USA were found to be the two leading countries with regard to the number of coproduced articles in the field of anatomy and ORL. In a study which compared the articles published in 11 journals with the

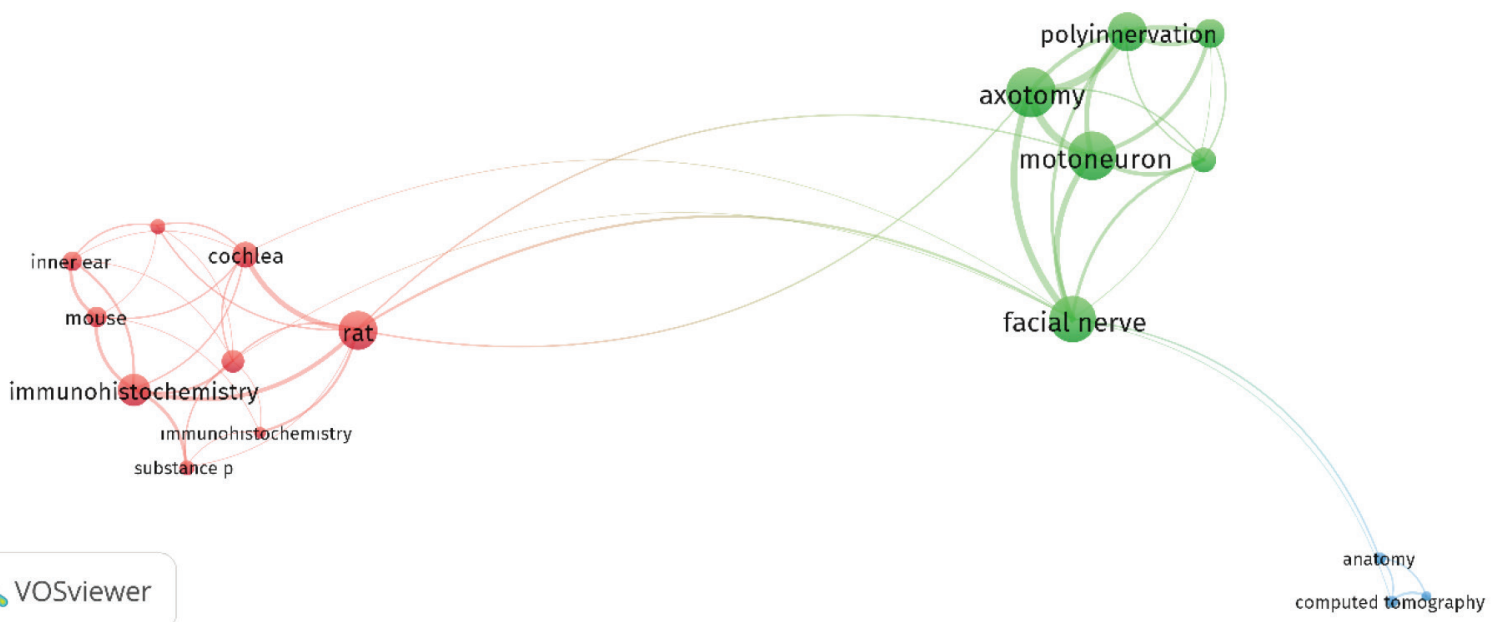

Figure 3: Network visualization map for cluster analysis based on keyword analysis on analysis of mutual publications of anatomists and otorhinolaryngologists from 1980-2020 (the size of the circle indicates a large number of publications; thick lines indicate strong relationship and colors indicate cluster idem). 


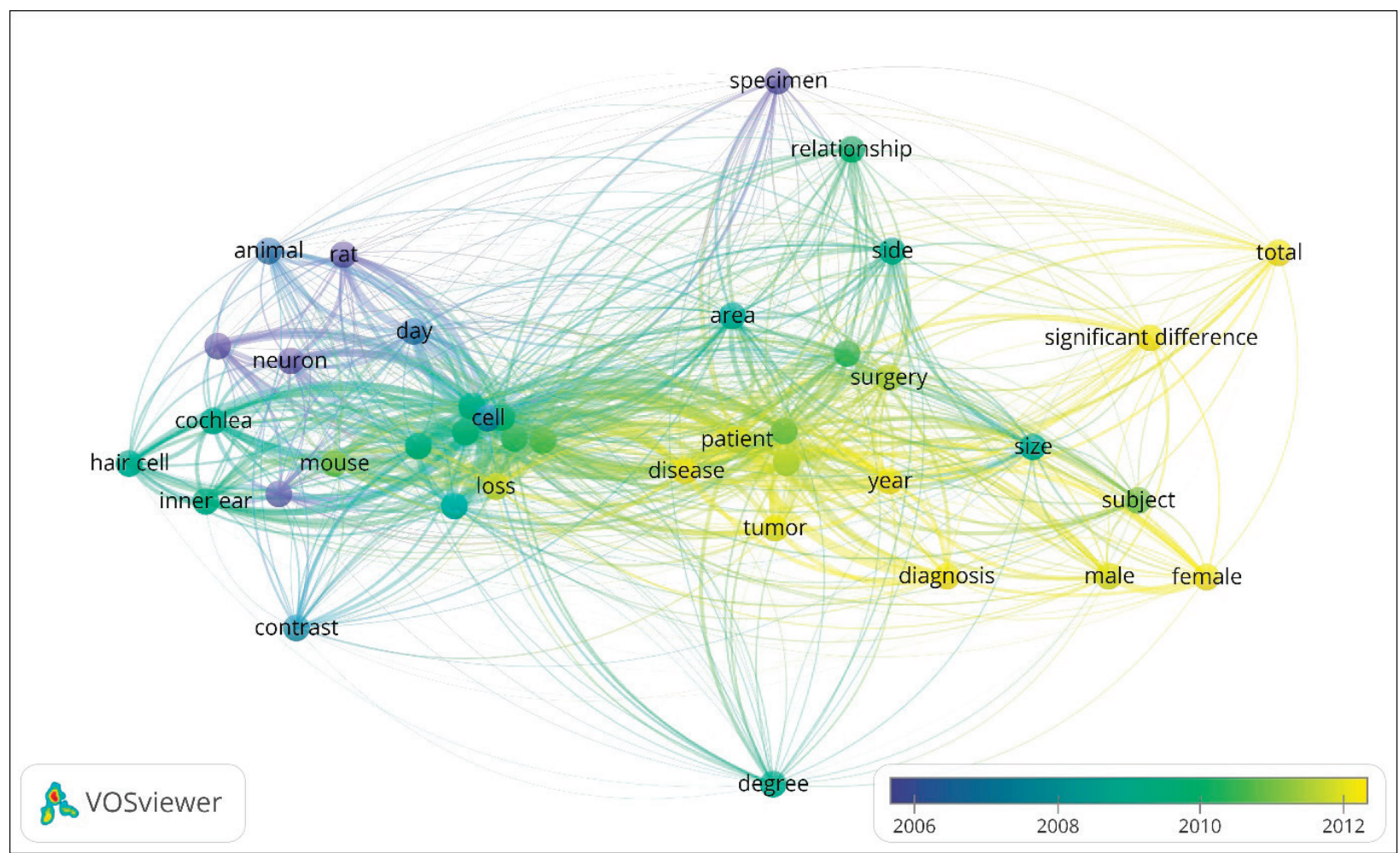

Figure 4: Network visualization map for trends based on keyword analysis on analysis of mutual publications of anatomists and otorhinolaryngologists from 1980-2020 (indicator shows current publications from blue to yellow).

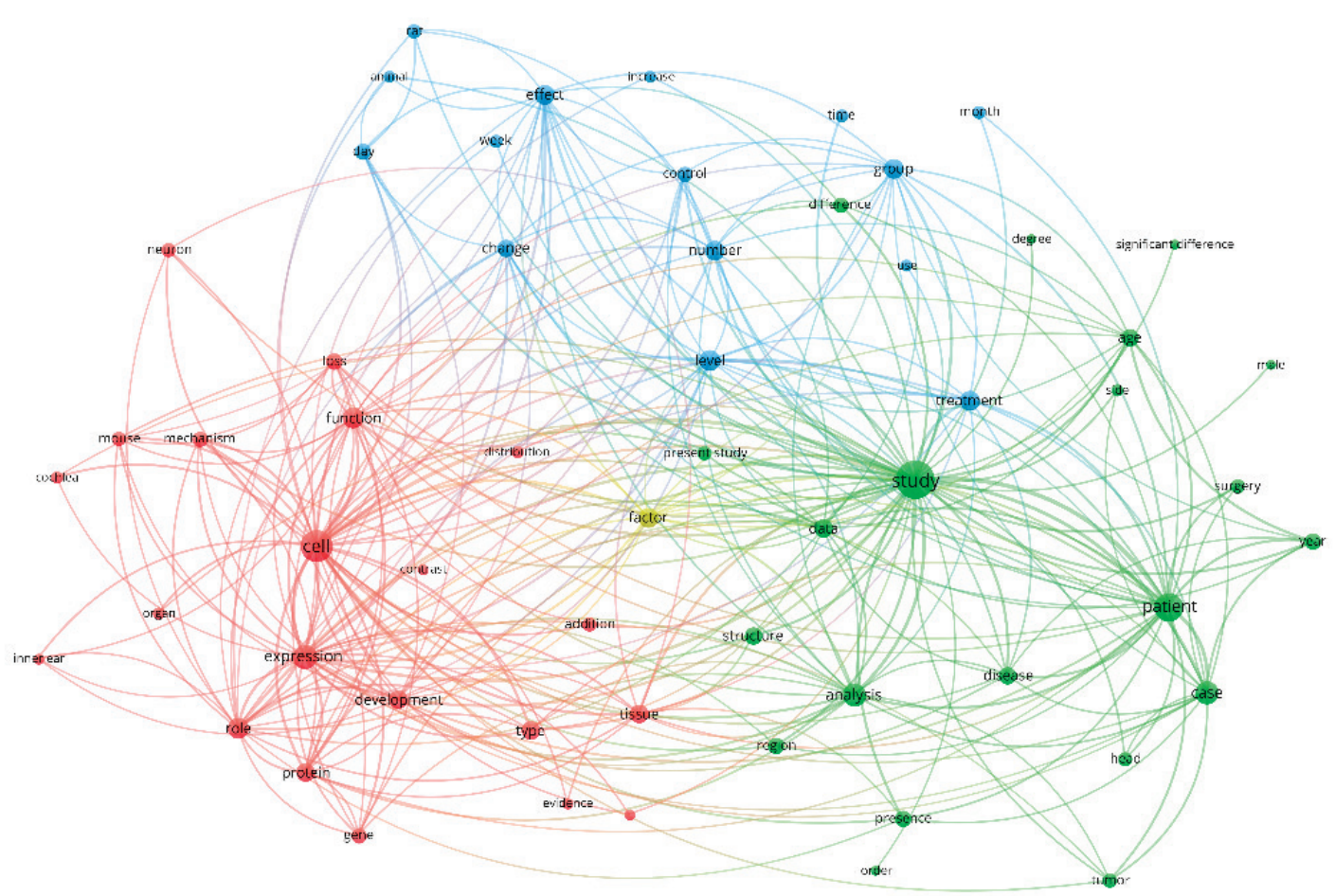

Mosviewer

Figure 5: Network visualization map for cluster analysis based on abstract analysis on analysis of mutual publications of anatomists and otorhinolaryngologists from 1980-2020 (the size of the circle indicates a large number of publications; thick lines indicate strong relationship and colors indicate cluster idem). 


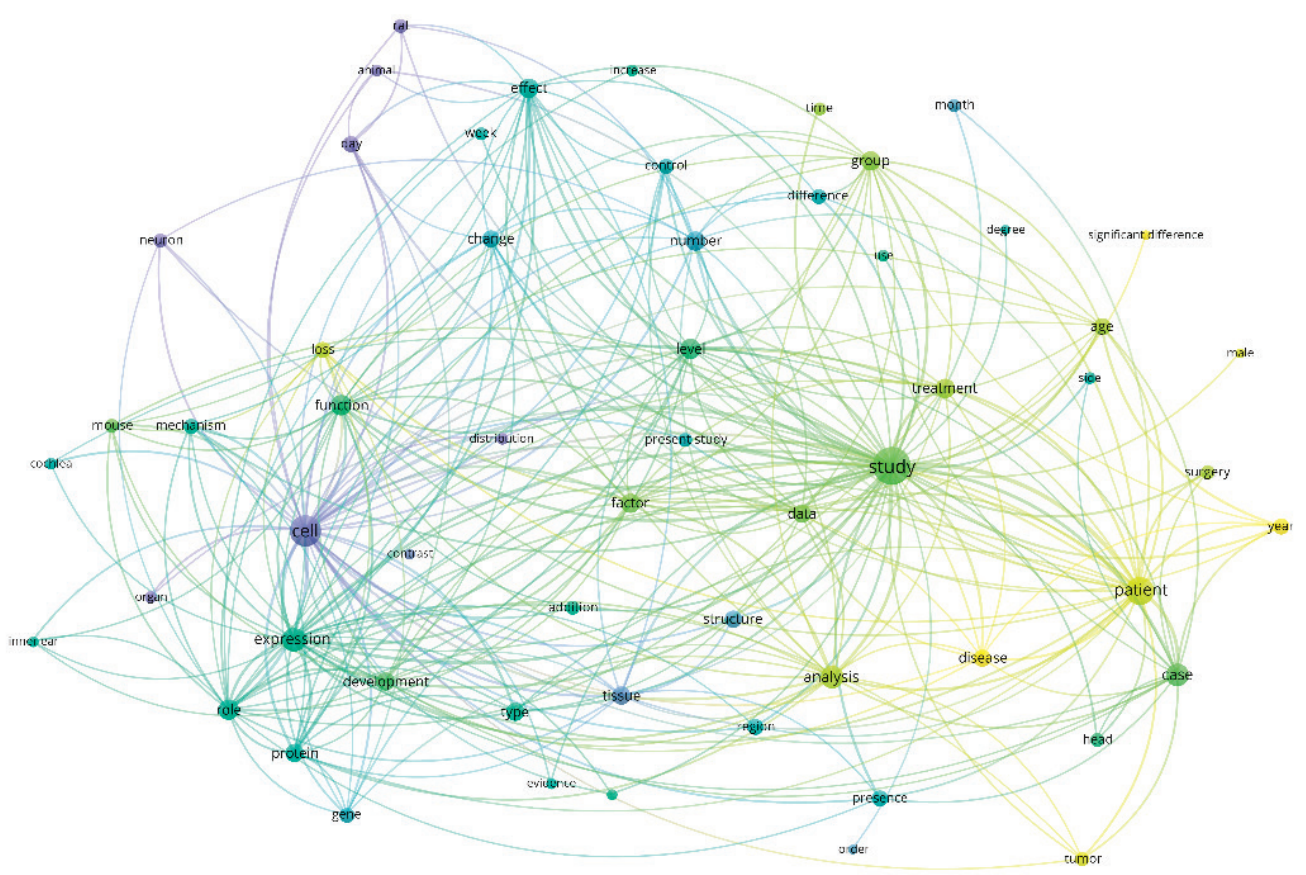

急 vosviewer

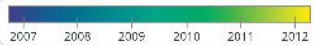

Figure 6: Network visualization map for trends based on abstract analysis on analysis of mutual publications of anatomists and otorhinolaryngologists from 1980-2020 (indicator shows current publications from blue to yellow).

highest impact factor between 2009 and 2013, Japan stood out as the country with the highest growth curve (18). The increase seen in the USA for the production of articles may be associated with greater research funds being awarded. More specifically, the National Health Institutes in USA are reported to have received awards of 30 billion dollars for medical research in 2014 (21). In developing countries, including Africa, some researchers make studies on their own or independently instead of collaborating with developed countries (22). This may be one of the reasons why developing countries produce fewer articles as compared to the other parts of the world. Also, in our study, there are no African countries among the first leading 25 countries. We consider that this problem may be solved through bringing international collaboration resources and the researchers in developing countries together. When the mutual articles in the field of anatomy and ORL were analyzed with regard to distribution according to universities, about onethird of the first leading 20 universities were seen to be located in the USA. This performance may be associated with national and international collaborations that could affect the visibility of the research and frequency of citations (23) alongside the availability of economic power, support funds, and research opportunities $(24,25)$. In addition, in a bibliometric analysis evaluating university-industry relationships in the USA, it was emphasized that universities had high-quality research environments that have strong research bonds (26). In conclusion, it is seen that many qualified articles can be produced when a trained workforce and sufficient financial and technological support come together. Identifying the universities where co-published articles in anatomy and ORL are produced will guide young researchers interested in the subject in terms of future research environments.

The journals that are active in a certain research field may be identified by detecting the distribution of the articles related to that subject and the researchers may select journals accordingly (20). Callaham et al. (27) reported that an article published in a journal with a low impact factor attracts less attention than it deserves, and an article published in a journal with a high impact factor attracts more attention than it deserves. From this point of view, bibliometric analysis can help find active journals in the field of research, guiding researchers to get their articles more accepted.

The keywords in an article indicate the relevant points in the related article (28). These points not only represent those key elements but also the potential trends of future research (29). As authors use prominent points as keywords in their articles, it is important to easily scan the frequency and distribution of keywords in the article using bibliometric analysis to highlight the important points of the topic. In co-published articles in the field of ORL and anatomy, the three most common keywords are "cochlea", "facial nerve" and "inner ear" in the field of otology. In an anatomy study conducted in the field of a cochlear implant, the significant increase in cochlear implant procedures in recent years has led to the need for a detailed and accurate understanding of the anatomy of the inner ear not only from the point of view of experimental scientists but also from the point of view of otorhinolaryngologists 
(30). Furthermore, together with the integration of robotic techniques in cochlear implant surgery in recent years (31), many anatomical cadaver studies have been conducted which evaluated facial nerves and the other anatomic structures in the inner ear and indicated the feasibility of robotic technology (32-35). In terms of determining the boundaries of future research areas, this study shows that any technological development integrated into interventional treatment, such as in robotic cochlear implant surgery, can be supported by anatomical studies.

As part of medical education, it was emphasized that teamwork skills should be developed, and researchers should work with different disciplines where the responsibilities of health care workers are shared, and abilities overlap (36). It has been stated that anatomy studies are part of medical education along with other disciplines in cadaver studies related to the human body (37). The present study, which evaluated co-published articles in the field of anatomy and ORL over the past 40 years, shows that research between different disciplines on the subject is gradually increasing and suggests that there will be more in the future. We consider that this study might guide young researchers who plan to study in the field of anatomy and ORL in terms of ideas and foresight.

Our analyses are based on the articles reported in $\mathrm{SCl}-\mathrm{E}$ in the WoS database over the last 40 years. While data analysis is relatively objective and comprehensive, it has some limitations specific to bibliometric methodology. Databases other than the WoS, for example, Scopus, Pubmed, and Google Scholar were not included since many databases could not be technically joined. Moreover, the language of WoS is English, although it is a global tool. As a result, several articles might be overlooked as articles published in other languages are not included. Finally, the database is still open, and the research can continuously be updated. Over time, these data should be updated by comparing with the results in different databases.

\section{CONCLUSION}

Bibliometric analysis is an extremely useful tool for determining global publication trends in peer-reviewed journals and its importance is gradually increasing. Herein, we evaluated 1395 articles co-published in anatomy and ORL between 1980 and 2020 in terms of countries, institutes, journals, and keywords used. The results of our bibliometric study evaluating the last 40 years in terms of networks, collaborations, and institutions could be an inspiration and source for future researchers. We can state that with advances in technology, the applicability of interventional methods in the field of ORL might be increased by conducting more anatomical studies and yield safer results.

Ethics Committee Approval: Ethics committee approval was not received due to the nature of this study.

Informed Consent: Informed consent was not obtained due to the nature of the study.

Peer-Review: Externally peer-reviewed.
Author Contributions: Conception/Design of Study- A.M.T., i.B.; Data Acquisition- I.B.; Data Analysis/Interpretation- A.M.T., I.B.; Drafting Manuscript- A.M.T., I.B.; Critical Revision of Manuscript- A.M.T., I.B.; Final Approval and Accountability- A.M.T., i.B.

Conflict of Interest: Authors declared no conflict of interest.

Financial Disclosure: Authors declared no financial support.

\section{REFERENCES}

1. Bahşi I, Çetkin M, Orhan M. Anatomy of kidney: A comparative historical study. Eur J Ther 2016;22:66-71.

2. Bahşi I, Topal Z, Çetkin $M$, Orhan $M$, Kervancıoğlu $P$, Odabaşıŏlu $M E$, et al. Evaluation of attitudes and opinions of medical faculty students against the use of cadaver in anatomy education and investigation of the factors affecting their emotional responses related thereto. Surg Radiol Anat 2021;43(4):481-7.

3. McMenamin PG, McLachlan J, Wilson A, McBride JM, Pickering J, Evans $D$. et al. Do we really need cadavers anymore to learn anatomy in undergraduate medicine? Med Teach 2018;40(10):1020-9.

4. Grignon B. Anatomy and medical imaging: a symbiotic relationship. Surg Radiol Anat 2012;34(8):673-4.

5. Wing L, Massoud TF. Trends in performance indicators of neuroimaging anatomy research publications: a bibliometric study of major neuroradiology journal output over four decades based on web of science database. Clin Anat 2015;28(1):16-26.

6. Gualtieri T, Verzeletti V, Ferrari M, Perotti P, Morello R, Taboni S, et al. A new landmark for lingual artery identification during transoral surgery: Anatomic-radiologic study. Head Neck 2021;43(5):1487-98.

7. Noiphithak R, Yanez-Siller JC, Revuelta Barbero JM, Otto BA, Carrau RL, Prevedello DM. Comparative Analysis Between Lateral Orbital Rim Preservation and Osteotomy for Transorbital Endoscopic Approaches to the Cavernous Sinus: An Anatomic Study. Oper Neurosurg (Hagerstown) 2019;16(1):86-93.

8. Vural A, Carobbio ALC, Ferrari M, Rampinelli V, Schreiber A, Mattavelli $D$, et al. Transorbital endoscopic approaches to the skull base: a systematic literature review and anatomical description. Neurosurg Rev 2021;44:2857-78.

9. Bahşi I, Orhan M, Kervancıoğlu P, Yalçın ED. The anatomical and radiological evaluation of the Vidian canal on cone-beam computed tomography images. Eur Arch Otorhinolaryngol 2019;276(5):137383.

10. Yang H, Pan BC, Chen J. Citation analysis of five journals in andrology. Arch Androl 2006;52(6):433-40.

11. Adanır SS, Bahşi I, Kervancıoğlu P, Orhan M, Cihan ÖF. Bibliometric analysis of articles published in Anatomy, the official publication of the Turkish Society of Anatomy and Clinical Anatomy between 2007-2018. Anatomy 2020;14(1):39-43.

12. Aria M, Cuccurullo C. bibliometrix: An R-tool for comprehensive sciencemappinganalysis.JournalofInformetrics 2017;11(4):959-75.

13. Topal Z, Bahsi I, Tufan AE. Evaluation of The Psychiatric Research Output From Turkey Via Web Of Science Database: A Bibliometric Analysis. Psychiatry Clin Psychopharmacol 2020;30(4):423-33.

14. Miao L, Ji J, Wan L, Zhang J, Yin L, Pu Y. An overview of research trends and genetic polymorphisms for noise-induced hearing loss from 2009 to 2018. Environ Sci Pollut Res Int 2019;26(34):3475474. 
15. Tekin AM, Bahşi I. Global Research on Maxillofacial Fracture over the last 40 years: A Bibliometric Study. J Craniofac Surg 2021;32(6):e568-72. doi: 10.1097/SCS.0000000000007627.

16. Shi M, Huang W, Shu L, Hou G, Guan Y, Song G. Research on polycystic ovary syndrome: a bibliometric analysis from 2009 to 2019. Gynecol Endocrinol 2021;37(2):121-5.

17. Kulkarni AV, Aziz B, Shams I, Busse JW. Comparisons of citations in Web of Science, Scopus, and Google Scholar for articles published in general medical journals. Jama 2009;302(10):1092-6.

18. Saunders TFC, Rymer BC, McNamara KJ. A global bibliometric analysis of otolaryngology: Head and neck surgery literature. Clin Otolaryngol 2017;42(6):1338-42.

19. Xue T, Wei L, Zha DJ, Qiao L, Qiu JH, Lu LJ, et al. Publications about hearing in otorhinolaryngology journals from chinese authors: a 11-year survey of the literature. Indian J Otolaryngol Head Neck Surg 2012;64(2):106-9.

20. Gao H, Huang FY, Wang ZP. Research Trends of Macrophage Polarization: A Bibliometric Analysis. Chin Med J (Engl) 2018;131(24):2968-75.

21. Grepin KA, Pinkstaff CB, Shroff ZC, Ghaffar A. Donor funding health policy and systems research in low- and middle-income countries: how much, from where and to whom. Health Res Policy Syst 2017;15:68.

22. Vanni T, Mesa-Frias M, Sanchez-Garcia R, Roesler R, Schwartsmann G, Goldani MZ, et al. International scientific collaboration in HIV and HPV: a network analysis. PLoS One 2014;9(3):e93376.

23. Li T, Ho YS, Li CY. Bibliometric analysis on global Parkinson's disease research trends during 1991-2006. Neurosci Lett 2008;441(3):24852.

24. Ekundayo TC, Okoh Al. A global bibliometric analysis of Plesiomonasrelated research (1990 - 2017). PLoS One 2018;13(11):e0207655.

25. Zyoud SH. Global toxocariasis research trends from 1932 to 2015 : a bibliometric analysis. Health Res Policy Syst 2017;15(1):14.

26. Zhou P, Tijssen R, Leydesdorff L. University-Industry Collaboration in China and the USA: A Bibliometric Comparison. PLoS One 2016;11(11):e0165277. doi: 10.1371/journal.pone.0165277.

27. Callaham M, Wears RL, Weber E. Journal prestige, publication bias, and other characteristics associated with citation of published studies in peer-reviewed journals. Jama 2002;287(21):2847-50.
28. Zongyi Y, Dongying C, Baifeng L. Global Regulatory T-Cell Research from 2000 to 2015: A Bibliometric Analysis. PLoS One 2016;11(9):e0162099. doi: 10.1371/journal.pone.0162099.

29. Shen S, Cheng C, Yang J, Yang S. Visualized analysis of developing trends and hot topics in natural disaster research. PLoS One. 2018;13(1):e0191250. doi: 10.1371/journal.pone.0191250.

30. Mehanna AM, Abdelnaby MM, Eid M. The Anatomy and Anatomical Variations of the Round Window Prechamber and Their Implications on Cochlear Implantation: An Anatomical, Imaging, and Surgical Study. Int Arch Otorhinolaryngol 2020;24(3):e288-98. doi: 10.1055/s-0039-1698783.

31. Tekin AM, Matulic M, Wuyts W, Assadi MZ, Mertens G, Rompaey VV, et al. A New Pathogenic Variant in POU3F4 Causing Deafness Due to an Incomplete Partition of the Cochlea Paved the Way for Innovative Surgery. Genes (Basel) 2021;12(5):613.

32. Rathgeb C, Wagner F, Wimmer W, Gerber N, Williamson T, Anschütz $L$, et al. The accuracy of image-based safety analysis for robotic cochlear implantation. Int J Comput Assist Radiol Surg 2019;14(1):83-92.

33. Schneider D, Stenin I, Anso J, Hermann J, Mueller F, Pereira Bom Braga $G$, et al. Robotic cochlear implantation: feasibility of a multiport approach in an ex vivo model. Eur Arch Otorhinolaryngol 2019;276(5):1283-9.

34. Torres R, Jia H, Drouillard M, Bensimon JL, Sterkers O, Ferrary E, et al. An Optimized Robot-Based Technique for Cochlear Implantation to Reduce Array Insertion Trauma. Otolaryngol Head Neck Surg 2018;159(5):900-7.

35. Torres R, Kazmitcheff G, De Seta D, Ferrary E, Sterkers O, Nguyen Y. Improvement of the insertion axis for cochlear implantation with a robot-based system. Eur Arch Otorhinolaryngol 2017;274(2):71521.

36. Hall P, Weaver L. Interdisciplinary education and teamwork: a long and winding road. Med Educ 2001;35(9):867-75.

37. Greene JR. Design and development of a new facility for teaching and research in clinical anatomy. Anat Sci Educ 2009;2(1):34-40. 